\title{
Bittersweet: infective complications of drug-induced glycosuria in patients with diabetes mellitus on SGLT2-inhibitors: two case reports
}

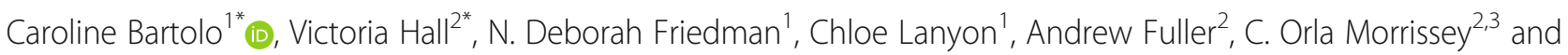
Eugene Athan ${ }^{1,4}$

\begin{abstract}
Background: Sodium-glucose co-transporter 2 (SGLT2) inhibitors are novel hypoglycemic agents which reduce reabsorption of glucose at the renal proximal tubule, resulting in significant glycosuria and increased risk of genital mycotic infections (GMI). These infections are typically not severe as reported in large systematic reviews and metaanalyses of the medications. These reviews have also demonstrated significant cardiovascular benefits through other mechanisms of action, making them attractive options for the management of Type 2 diabetes mellitus (T2DM). We present two cases with underlying abnormalities of the urogenital tract in which the GMI were complicated and necessitated cessation of the SGLT2 inhibitor.
\end{abstract}

Case presentations: Both cases are patients with T2DM on empagliflozin, an SGLT2 inhibitor. The first case is a 64 year old man with Candida albicans balanitis and candidemia who was found to have an obstructing renal calculus and prostatic abscess requiring operative management. The second case describes a 72 year old man with Candida glabrata candidemia who was found to have prostatomegaly, balanitis xerotica obliterans with significant urethral stricture and bladder diverticulae. His treatment was more complex due to fluconazole resistance and concerns about urinary tract penetration of other antifungals. Both patients recovered following prolonged courses of antifungal therapy and in both cases the SGLT2 inhibitor was ceased.

Conclusions: Despite their cardiovascular benefits, SGLT2 inhibitors can be associated with complicated fungal infections including candidemia and patients with anatomical abnormalities of the urogenital tract may be more susceptible to these infections as demonstrated in these cases. Clinicians should be aware of their mechanism of action and associated risk of infection and prior to prescription, assessment of urogenital anatomical abnormalities should be performed to identify patients who may be at risk of complicated infection.

Keywords: Candidemia, SGLT2 inhibitor, Glycosuria, Case report, Genital mycotic infection, Prostatic abscess

\footnotetext{
*Correspondence: caroline.bartolo@barwonhealth.org.au; victoria.hall@uhn.ca

${ }^{1}$ Department of Infectious Diseases, Barwon Health, Geelong, Victoria,

Australia

${ }^{2}$ Department of Infectious Diseases, Alfred Hospital, Melbourne, Victoria,

Australia

Full list of author information is available at the end of the article
}

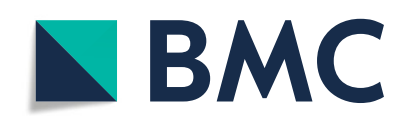

(- The Author(s). 2021 Open Access This article is licensed under a Creative Commons Attribution 4.0 International License, which permits use, sharing, adaptation, distribution and reproduction in any medium or format, as long as you give appropriate credit to the original author(s) and the source, provide a link to the Creative Commons licence, and indicate if changes were made. The images or other third party material in this article are included in the article's Creative Commons licence, unless indicated otherwise in a credit line to the material. If material is not included in the article's Creative Commons licence and your intended use is not permitted by statutory regulation or exceeds the permitted use, you will need to obtain permission directly from the copyright holder. To view a copy of this licence, visit http://creativecommons.org/licenses/by/4.0/. The Creative Commons Public Domain Dedication waiver (http://creativecommons.org/publicdomain/zero/1.0/) applies to the data made available in this article, unless otherwise stated in a credit line to the data. 


\section{Background}

Sodium-glucose cotransporter 2 (SGLT2) inhibitors are novel oral hypoglycemic agents which inhibit the reuptake of filtered sodium and glucose at the proximal convoluted tubule. Large drug efficacy trials have found substantial improvement in glycemic control, weight loss, a reduction in blood pressure and cardiovascular mortality; so, are an attractive option for the management of Type 2 diabetes mellitus (T2DM) [1-6].

SGLT2 inhibitors cause significant glycosuria, associated with a nearly five-fold increased risk of genital mycotic infections (GMI; balanitis in men and vulvovaginitis in women) [4]. We describe two cases of candidemia secondary to GMI in patients on SGLT2 inhibitors, which led to significant morbidity and the subsequent discontinuation of the SGLT2 inhibitor.

\section{Case presentations}

A 64-year-old man with T2DM, managed with empagliflozin 10mg daily, which had been commenced 2 years prior, metformin and sitagliptin, presented to the emergency department with progressive lethargy, fevers and dysuria. The symptoms had progressed despite receiving 5 days of oral cephalexin a few weeks prior following collection of a urine sample which grew Candida albicans alone. On examination, he was febrile $\left(39.6^{\circ} \mathrm{C}\right)$, tachycardic (108 beats per minute) and hypotensive (87/ $55 \mathrm{mmHg}$ ) and blood sugar level (BSL) was measured at $39 \mathrm{mmol} / \mathrm{L}(702 \mathrm{mg} / \mathrm{dL})$. Examination revealed balanoposthitis but was otherwise unremarkable.

Initial investigations showed significantly raised inflammatory markers: C-reactive protein (CRP) of $287 \mathrm{mg} / \mathrm{L}$, total white blood cell count (WCC) of $32.1 \times 10^{9} / \mathrm{L}$ with a predominant neutrophilia of $28.2 \times 10^{9} / \mathrm{L}$ and acute kidney injury with serum creatinine $208 \mu \mathrm{mol} / \mathrm{L} \quad(\mathrm{CrCl} 28 \mathrm{ml} / \mathrm{min}) . \mathrm{HbA} 1 \mathrm{C}$ was $11.0 \%(<5.7 \%)$ and prostate specific antigen (PSA) $2.76 \mathrm{mcg} / \mathrm{L}(<4.51 \mathrm{mcg} / \mathrm{L})$.

He was transferred to the intensive care unit (ICU) for inotropic support; $24 \mathrm{~h}$ into his admission a yeast was identified from two sets of blood cultures and he was commenced on intravenous (IV) anidulafungin. Candida albicans was subsequently isolated from blood, urine and urethral swab cultures. The minimum inhibitory concentration (MIC) for fluconazole was $<0.05 \mu \mathrm{g} / \mathrm{L}$ (susceptible) and he was changed to IV fluconazole 400mg daily.

An abdomino-pelvic computed tomography scan demonstrated right-sided emphysematous pyelonephritis, a $7 \mathrm{~mm}$ non-obstructing calculus in the right renal pelvis, a large $(57 \times 43 \times 65 \mathrm{~mm})$ bladder diverticulum and emphysematous prostatitis. As he remained candidemic, repeat imaging on day 7 demonstrated gas in the prostate and that the renal calculus had migrated to the proximal ureter causing acute obstruction necessitating the urgent insertion of a nephrostomy tube. On day 12 he underwent anterograde ureteric stent insertion. A transperineal ultrasound on day 13 confirmed the presence of a prostatic abscess requiring cystoscopy, transurethral drainage of the prostatic abscess and transurethral resection of the prostate. Culture of the abscess grew C. albicans (fluconazole $\mathrm{MIC}<0.05 \mu \mathrm{g} / \mathrm{L}$ ). Transesophaegeal echocardiography and ophthalmological examination were normal. The SGLT2 inhibitor was ceased and he was discharged home on oral fluconazole 400mg daily with an indwelling urinary catheter (IDC).

Three weeks later whilst still on fluconazole, he had an episode of fever and right flank pain. The renal calculus, stent and catheter were removed. He received a total of 6 weeks of fluconazole and recovered.

A 72-year-old man presented emergently to hospital after having driven his car into a concrete barrier at low speed. He was febrile and confused. He had a history of T2DM, managed with metformin and empagliflozin $10 \mathrm{mg}$ daily; the latter prescribed only 2 months prior. Examination did not reveal any injury sustained from the collision; however, it was significant for balanitis with a tender prostate and he was in acute urinary retention. BSL was significantly raised at $22.2 \mathrm{mmol} / \mathrm{L}$ (400mg/dL).

Investigations revealed a CRP of $261 \mathrm{mg} / \mathrm{L}$, total WCC of $14.4 \times 10^{9} / \mathrm{L}$ with a neutrophilia $\left(13.4 \times 10^{9} / \mathrm{L}\right)$, acute kidney injury with serum creatinine $113 \mu \mathrm{mol} / \mathrm{L}(\mathrm{CrCl}$ $55 \mathrm{~mL} / \mathrm{min})$. HbA $1 \mathrm{C}$ was $9.0 \%(<5.7 \%)$ and PSA was $8.8 \mathrm{mcg} / \mathrm{L}(<4.51 \mathrm{mcg} / \mathrm{L})$. Blood cultures grew a yeast at $36 \mathrm{~h}$ and the patient was commenced empirically on IV caspofungin. The yeast was identified as Candida glabrata; urine and urethral swab specimens were also culture positive for $C$. glabrata. For all isolates the same susceptibility profile was observed, with a fluconazole MIC of $128 \mu \mathrm{g} / \mathrm{L}$ (resistant). Susceptibility was confirmed to caspofungin $(\mathrm{MIC} 0.06 \mu \mathrm{g} / \mathrm{L}), 5$ - flucytosine (MIC $\leq 0.06 \mu \mathrm{g} / \mathrm{L}$ ) and amphotericin B (MIC $0.5 \mu \mathrm{g} / \mathrm{L})$. Blood culture clearance occurred after $48 \mathrm{~h}$ of caspofungin.

A renal tract ultrasound demonstrated prostatic enlargement, bladder diverticulae and an elevated postvoid residual volume ( $>300 \mathrm{mls})$. On day 5 of his admission, he underwent rigid cystoscopy and urethral dilatation with the significant findings of a pinpoint meatal urethral stricture, glandular adhesions and balanitis xerotica obliterans. During the procedure an IDC was inserted to relieve the bladder outlet obstruction. Transthoracic echocardiogram and ophthalmological examination were normal.

Caspofungin was changed to micafungin 100mg IV daily. Fluconazole was added and the dose was reduced from $1200 \mathrm{mg}(10 \mathrm{mg} / \mathrm{kg})$ to $800 \mathrm{mg}$ daily due to QTc prolongation. 5-flucytosine $25 \mathrm{mg} / \mathrm{kg}$ QID was added. $\mathrm{He}$ 
received a total of 4 weeks treatment with clinical and microbiological cure. The SGLT2 inhibitor was ceased.

\section{Discussion \& Conclusions}

SGLT2 inhibitors are selective membrane transport inhibitors which act on the proximal convoluted tubule and prevent glucose and sodium absorption back into the circulation resulting in glycosuria. In a randomised, placebo-controlled trial in patients taking varying doses of empagliflozin, urinary glucose excretion reached up to $90 \mathrm{~g} /$ day [1]. The average daily volume of urine excreted by participants was 31 equating to a urinary glucose concentration of $30 \mathrm{~g} / \mathrm{L}$, roughly equivalent to that of Sabouraud agar, the preferred growth medium for optimal yeast culture including Candida species providing a biologically plausible explanation for the observed increased risk of GMI.

Patients with T2DM are more likely to have genital tract colonisation with Candida spp [7] and the risk of GMI is higher in patients with diabetes. In a populationbased study, in the UK, diabetic women had a risk ratio of 1.81 (95\% CI 1.64-2.0) for vaginitis and men had a risk ratio of 2.85 (2.84-4) for balanitis compared with those without diabetes [7]. A number of systematic reviews and meta-analyses, to date, have shown a 4- to 8fold increased risk of GMI in patients taking SGLT2 inhibitors compared with placebo or other hypoglycemic agents $[2-6,8]$. Mechanisms for this increased risk include increased adherence of Candida to the genital tract and reduced host immune response in patients with T2DM [9]. This, combined with the further increase in glycosuria in patients on SGLT2 inhibitor therapy and pre-existing anatomical abnormalities of the urogenital tract may predispose to complicated urinary tract infection (UTI).

The U.S. Food and Drug Administration (FDA) issued a warning about the risk of complicated UTI in patients taking SGLT2 inhibitors in 2015 after 19 cases of complicated UTI were reported from March 2013 through October 2014. In contrast, a large population-based cohort study found no increased risk of serious UTI in patients taking an SGLT2 inhibitor compared with other hypoglycemic agents. However, this study excluded patients with higher risk of UTI (including those with anatomical abnormalities such as prostatomegaly and obstructive defects of the renal pelvis and ureter including calculi) [10]. In patients with a higher predisposition for severe UTI, complications can include candidemia which is associated with up to $47 \%$ mortality, endophthalmitis and endocarditis [11].

Duration of therapy for fungal prostatic abscess and candidemia from a urinary tract source are not welldefined. These two cases were treated for 4-6 weeks. Case 1 had prolonged candidemia until source control (abscess drainage) was achieved. It has been reported that successful treatment of Candida prostatitis has been achieved with micafungin when paired with surgical drainage [12]. Case 2 highlights the potential challenges in treating fluconazole-resistant Candida spp infection from a urinary tract source.

Fluconazole is the usual drug of choice for Candida UTI [11, 13, 14]. It is mostly eliminated unchanged $(80 \%)$ in the urine resulting in urinary concentrations that are 10-20 times that of plasma (levels $>100 \mu \mathrm{g} / \mathrm{ml}$ ) $[11,13,14]$. Therefore, urinary concentrations are able to exceed MIC for susceptible but dose dependent (MIC $16-32 \mu \mathrm{g} / \mathrm{mL}$ ) and even resistant (MIC $>64 \mu \mathrm{g} / \mathrm{mL}$ ) isolates. Higher dosing of fluconazole $(12 \mathrm{mg} / \mathrm{kg})$ is often recommended for the treatment of susceptible C. glabrata infections; however, there are limited clinical data to support this advice [14-16]. Other azoles (e.g. posaconazole, voriconazole) are minimally excreted in the urine and therefore not recommended [11, 14]. Flucytosine has broad anti-fungal activity and excellent oral bioavailability, is mostly excreted unchanged in urine (97\%) and similarly achieves high urinary concentrations $(\sim 60$ times that of plasma) $[11,14,16]$. It is usually given in combination as resistance can develop when it is used as monotherapy; due to its short half-life it is dosed at $25 \mathrm{mg} / \mathrm{kg} 4$ times daily and therapeutic drug monitoring is recommended (as in case 2) [11, 14, 16]. There is emerging evidence that echinocandins, particularly micafungin, can achieve adequate clinical efficacy when correlated with PK/PD ratios [17]; and in the treatment of candidemia from a urinary tract source, similar outcomes have been achieved with echinocandins compared with fluconazole [18]. Case 2 was thus treated with a combination of high dose fluconazole plus flucytosine for optimal penetration into the urinary tract, with the addition of micafungin due to the severity of the infection.

SGLT2 inhibitors are prescribed more frequently in T2DM due to their favorable cardiovascular outcomes. However, as demonstrated in these cases, there appears to be an associated increased risk of complicated fungal infection in patients with underlying abnormalities of the urogenital tract. We suggest that prior to the prescription of SGLT2 inhibitors, urogenital abnormalities should be identified and treated. The risks and benefits of these medications should be discussed with the patient and alternate hypoglycemic agents considered if the risk of GMI is considered to outweigh the benefits.

\section{Abbreviations}

SGLT2: Sodium-glucose co-transporter 2; GMI: Genital mycotic infections; T2DM: Type 2 diabetes mellitus; BSL: Blood sugar level; CRP: C-reactive protein; WCC: White blood cell count; CrCl: Creatinine clearance; HbA1c: Glycated haemoglobin; PSA: Prostate specific antigen; ICU: Intensive care unit; IV: Intravenous; MIC: Minimum inhibitory concentration; 
IDC: Indwelling catheter; QTc: Corrected QT interval; UTI: Urinary tract infection

\section{Acknowledgements}

Not applicable.

\section{Authors' contributions}

$C B, V H, \& C L$ wrote the case presentations. CB, VH \& NDF were the major contributors to the discussion. NDF \& EA were involved in the clinical management of Case 1. AF and COM were involved in the clinical management of Case 2. All authors read and approved the final manuscript.

\section{Funding}

The authors received no financial support for the research, authorship or publication of this article.

\section{Availability of data and materials}

Not applicable.

\section{Declarations}

\section{Ethics approval and consent to participate}

Not applicable.

\section{Consent for publication}

Both patients have provided written consent for publication and this can be provided if requested by the editors.

\section{Competing interests}

The authors declare that they have no competing interests.

\section{Author details}

'Department of Infectious Diseases, Barwon Health, Geelong, Victoria, Australia. ${ }^{2}$ Department of Infectious Diseases, Alfred Hospital, Melbourne, Victoria, Australia. ${ }^{3}$ Monash University, Melbourne, Victoria, Australia. ${ }^{4}$ Deakin University, Melbourne, Victoria, Australia.

Received: 21 December 2020 Accepted: 11 March 2021

Published online: 20 March 2021

\section{References}

1. Heise T, Seewaldt-Becker E, Macha S, Hantel S, Pinnetti S, Seman L, Woerle HJ. Safety, tolerability, pharmacokinetics and pharmacodynamics following 4 weeks' treatment with empagliflozin once daily in patients with type 2 diabetes. Diabetes Obes Metab. 2013;15(7):613-21. https://doi.org/10.1111/ dom.12073.

2. Monami M, Nardini C, Mannucci E. Efficacy and safety of sodium glucose co-transport-2 inhibitors in type 2 diabetes: a meta-analysis of randomized clinical trials. Diabetes Obes Metab. 2014;16(5):457-66. https://doi.org/1 $0.1111 /$ dom.12244

3. Zaccardi F, Webb DR, Htike ZZ, Youssef D, Khunti K, Davies MJ. Efficacy and safety of sodium-glucose co-transporter-2 inhibitors in type 2 diabetes mellitus: systematic review and network meta-analysis. Diabetes Obes Metab. 2016;18(8):783-94. https://doi.org/10.1111/dom.12670.

4. Storgaard H, Gluud LL, Bennett C, Grøndahl MF, Christensen MB, Knop FK Vilsbøll T. Benefits and harms of sodium-glucose co-transporter 2 inhibitors in patients with type 2 diabetes: a systematic review and meta-analysis. PLoS One. 2016;11(11):e0166125. https://doi.org/10.1371/journal.pone.01 66125.

5. Zheng SL, Roddick AJ, Aghar-Jaffar R, Shun-Shin MJ, Francis D, Oliver N, Meeran K. Association between use of sodium-glucose cotransporter 2 inhibitors, glucagon-like peptide 1 agonists, and dipeptidyl peptidase 4 inhibitors with all-cause mortality in patients with type 2 diabetes: a systematic review and meta-analysis. JAMA. 2018;319(15):1580-91. https:// doi.org/10.1001/jama.2018.3024

6. Perkovic V, Jardine MJ, Neal B, Bompoint S, Heerspink HJL, Charytan DM, Edwards R, Agarwal R, Bakris G, Bull S, Cannon CP, Capuano G, Chu PL, de Zeeuw D, Greene T, Levin A, Pollock C, Wheeler DC, Yavin Y, Zhang H, Zinman B, Meininger G, Brenner BM, Mahaffey KW. Canagliflozin and renal outcomes in type 2 diabetes and nephropathy. N Engl J Med. 2019:380(24): 2295-306. https://doi.org/10.1056/NEJMoa1811744.
7. Hirji I, Andersson SW, Guo Z, Hammar N, Gomez-Caminero A. Incidence of genital infection among patients with type 2 diabetes in the UK general practice research database. J Diabetes Complicat. 2012;26(6):501-5. https:// doi.org/10.1016/j.jdiacomp.2012.06.012.

8. Wiviott SD, Raz I, Bonaca MP, Mosenzon O, Kato ET, Cahn A, Silverman MG, Zelniker TA, Kuder JF, Murphy SA, Bhatt DL, Leiter LA, McGuire DK, Wilding JPH, Ruff CT, Gause-Nilsson IAM, Fredriksson M, Johansson PA, Langkilde AM, Sabatine MS. Dapagliflozin and cardiovascular outcomes in type 2 diabetes. N Engl J Med. 2019;380(4):347-57. https://doi.org/10.1056/ NEJMoa1812389.

9. Nyirjesy P, Zhao Y, Ways K, Usiskin K. Evaluation of vulvovaginal symptoms and Candida colonization in women with type 2 diabetes mellitus treated with canagliflozin, a sodium glucose co-transporter 2 inhibitor. Curr Med Res Opin. 2012;28(7):1173-8. https://doi.org/10.1185/03007995.2012.697053.

10. Dave CV, Schneeweiss S, Kim D, Fralick M, Tong A, Patorno E. Sodiumglucose cotransporter 2 inhibitors and the risk of severe urinary tract infection. Ann Intern Med. 2019;171(4):248-56. https://doi.org/10.7326/M1 8-3136.

11. Pappas PG, Kaufmann CA, Andes DR, et al. Clinical guideline for the Management of Candidiasis: 2016 update by the Infectious Diseases Society of America. Clin Infect Dis. 2016;62(4):e1-50. https://doi.org/10.1093/cid/ civ933.

12. Gupta S, Liu-Young G, Mahnensmith R, Topal JE. Prostatic abscess with Candida glabrata treated with Micafungin. Infect Dis Clin Pract. 2008;16(6): 387-9. https://doi.org/10.1097/IPC.0b013e31816613f1.

13. Felton T, Troke PF, Hope WW. Tissue penetration of antifungal agents. Clin Microbiol Rev. 2014;27(1):68-88. https://doi.org/10.1128/CMR.00046-13.

14. Fisher JF, Sobel JD, Kauffman CA, Newman CA. Candida urinary tract infections - treatment. Clin Infect Dis. 2011;52(suppl 6):457-66.

15. Walsh TJ, Foulds G, Pizzo PA. Pharmacokinetics and tissue penetration of fluconazole in rabbits. Antimicrob Agents Chemother. 1989;33(4):467-9. https://doi.org/10.1128/AAC.33.4.467.

16. Pfaller MA, Diekama DJ, Sheehan DJ. Interpretive breakpoints for fluconazole and Candida revisited: a blueprint for the future of antifungal susceptibility testing. Clin Microbiol Rev. 2006;19(2):435-47. https://doi.org/10.1128/CMR.1 9.2.435-447.2006.

17. Grau S, Luque S, Echeverria-Esnal D, et al. Urinary micafungin levels are sufficient to treat urinary tract infections caused by Candida spp. Int J Antimicrob Agents. 2016;48(2):212-4. https://doi.org/10.1016/j.ijantimicag.2 016.05.010.

18. Cuervo G, Garcia-Vidal C, Puig-Asensio M, et al. Echinocandins compared to fluconazole for Candidemia of a urinary tract source: a propensity score analysis. Clin Infect Dis. 2017;64(10):1374-9.

\section{Publisher's Note}

Springer Nature remains neutral with regard to jurisdictional claims in published maps and institutional affiliations.

Ready to submit your research? Choose BMC and benefit from:

- fast, convenient online submission

- thorough peer review by experienced researchers in your field

- rapid publication on acceptance

- support for research data, including large and complex data types

- gold Open Access which fosters wider collaboration and increased citations

- maximum visibility for your research: over $100 \mathrm{M}$ website views per year

At BMC, research is always in progress.

Learn more biomedcentral.com/submission 